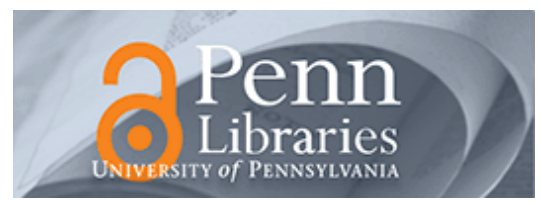

University of Pennsylvania

ScholarlyCommons

Management Papers

Wharton Faculty Research

$11-2003$

\title{
Political Hazards, Experience, and Sequential Entry Strategies: The International Expansion of Japanese Firms, 1980-1998
}

Andrew Delios

Witold J. Henisz

University of Pennsylvania

Follow this and additional works at: https://repository.upenn.edu/mgmt_papers

Part of the Business Administration, Management, and Operations Commons, and the International Business Commons

\section{Recommended Citation}

Delios, A., \& Henisz, W. J. (2003). Political Hazards, Experience, and Sequential Entry Strategies: The International Expansion of Japanese Firms, 1980-1998. Strategic Management Journal, 24 (11), 1153-1164. http://dx.doi.org/10.1002/smj.355

This paper is posted at ScholarlyCommons. https://repository.upenn.edu/mgmt_papers/54

For more information, please contact repository@pobox.upenn.edu. 


\title{
Political Hazards, Experience, and Sequential Entry Strategies: The International Expansion of Japanese Firms, 1980-1998
}

\author{
Abstract \\ expansions of 665 Japanese manufacturing firms, we build on the concepts of uncertainty and \\ our results is that research on international strategy should emphasize understanding the political \\ policy environment as a source of uncertainty to a firm, as it has given to cultural, social and market \\ institutions.

\section{Keywords} \\ stages model, internationalization, political risk, organizational learning, Japan \\ Disciplines \\ Business Administration, Management, and Operations | International Business
}

We find support for the role of experiential learning in the international expansion process by extending the stages model of internationalization to incorporate a sophisticated consideration of temporal and cross-national variation in the credibility of the policy environment. Using a sample of 3857 international experiential learning, to show that firms that had gathered relevant types of international experience were less sensitive to the deterring effect of uncertain policy environments on investment. One implication of institutions that constrain or enable political actors, just as entry mode research has done. A second implication is that research in the stages model of internationalization should give the same weight to the 


\title{
Political Hazards, Experience and Sequential Entry Strategies: The International Expansion of Japanese Firms, 1980-1998
}

\author{
ANDREW DELIOS \\ Department of Business Policy \\ National University of Singapore \\ 1 Business Link, Singapore 117592 \\ Tel: (65) 68743094 \\ Fax: (65) 6779-5059 \\ E-mail: andrew@nus.edu.sg \\ and \\ WITOLD J. HENISZ \\ Department of Management \\ The Wharton School \\ 2021 Steinberg Hall-Dietrich Hall \\ University of Pennsylvania \\ Philadelphia, PA 191046370 \\ Tel: (215) 898-0788 \\ Fax: (215) 898-0401 \\ E-mail: henisz@wharton.upenn.edu
}

September 12, 2002

\footnotetext{
* This research was supported by an RGC Grant (\#HKUST6217/00H) and by a Social Sciences and Humanities Research Council of Canada Grant (\#410-2001-0143). We thank Lorraine Eden, Ram Mudambi, Nicolaj Siggelkow and seminar participants at the Stern School of Business at New York University for their insightful comments and Freek Vermeulen for providing data for cultural distance measurements.
} 


\title{
Political Hazards, Experience and Sequential Entry Strategies: The International Expansion of Japanese Firms, 1980-1998
}

\begin{abstract}
.
We find support for the role of experiential learning in the international expansion process by extending the stages model of internationalization to incorporate a sophisticated consideration of temporal and cross-national variation in the credibility of the policy environment. Using a sample of 3,857 international expansions of 665 Japanese manufacturing firms, we build on the concepts of uncertainty and experiential learning, to show that firms that had gathered relevant types of international experience were less sensitive to the deterring effect of uncertain policy environments on investment. One implication of our results is that research on international strategy should emphasize understanding the political institutions that constrain or enable political actors, just as entry mode research has done. A second implication is that research in the stages model of internationalization should give the same weight to the policy environment as a source of uncertainty to a firm, as it has given to cultural, social and market institutions.
\end{abstract}

Key Words. stages model, internationalization, political risk, organizational learning, Japan 
An extensive literature on corporate expansions based in the stages model of internationalization (Johanson \& Vahlne, 1977; Luostarinen, 1980) examines how geographic distance and market, linguistic and cultural differences influence a firm's international expansion process across countries. We seek to extend this literature on the stages model to incorporate insight into how the political environment influences choices about which markets to enter for firms with different levels and types of international investment experience. We make this extension because scholars emphasize that political hazards area primary determinant of the likelihood of entry (Kobrin et. al. 1980). The stages model, however, has had a unitary focus in defining foreign market uncertainty as extending from cultural differences (Barkema et al., 1996). The omission of political hazards in extant stages models leaves these models incomplete and, as we find, could lead to poor empirical support for its main conjectures. Including the political environment in the stages model does not require an alteration of its core concepts - uncertainty and experiential learning - but it does require a multifaceted rather than unitary conceptualization of a nation's institutional environment.

In a stages model that omits consideration of the political environment, firms would be expected to move across markets of similar culture with relative ease. For example, firms would be expected to move sequentially from Singapore to Malaysia and Indonesia, from Chile to Peru and Paraguay or from Hungary to the Czech and Slovak Republics. Many firms did follow such patterns, but others held back noting that while similar in terms of markets and culture, these national markets differed in their political environments.

The empirical specification we develop to test for such patterns in foreign entry sequences extends the stages model while contributing to prior work on the deterring effect of uncertainty in the political environment (Delios \& Henisz, 2000; Henisz \& Delios, 2001) and the influence of experience on patterns of internationalization (Erramilli, 1991; Barkema et al., 1996; Delios \& Beamish, 2001). We refine the concept of international experience to develop specific profiles of experience that should be of particular importance to overcoming the uncer tainty that we model in our empirical setting. This study thus provides a better understanding of the sources of uncertainty in national institutional environments and identifies specific ways in which a firm sequences its expansion to minimize the uncerta inty that it encounters in each FDI entry. 


\section{BACKGROUND}

International expansion in the stages model is a process rooted in uncertainty reduction through the accumulation of relevant types of experience (Johanson \& Vahlne, 1977). Experience in a host country, for example, provides important information about its business environment (Luostarinen, 1980) thereby reducing uncertainty, and enabling a firm to make a better evaluation of potential future expansions (Barkema et al., 1996). Investment experience broadens a firm's perception of its alternatives and increases the extent of its search (Cyert \& March, 1963). The accumulation of international investment experience is reflected in two sequences of foreign entry: one from culturally and geographically close countries to more distant ones (Davidson, 1980), and one for a firm's investment path in a country, from exporting, to distribution, to joint venture manufacturing and finally wholly-owned manufacturing (Davidson, 1980).

These two sequences stem from a reduction in knowledge and skill barriers to foreign expansion that can accompany the accumulation of international experience (Henisz and Delios, 2001; Delios \& Beamish, 1999). Yet, within the aggregate measure of international experience, firms can have diverse experience profiles that le ad to different levels of learning about national environments, and hence different levels of uncertainty about those environments. Disaggregating experience into fine-grained profiles may be necessary to identify its effects on a firm's entry strategy. For example, previous research demonstrates that eperience gained in specific settings such as a subsidiary's industry, or the nation in which a subsidiary is sited, minimizes the deterring influence of political hazards on entry modes (Delios \& Henisz, 2000), and reduces a firm's tendency to follow the FDI entry location and entry mode decisions of other firms (Henisz \& Delios, 2001; Lu, 2001). National experience, however, does not diminish the negative influence of political hazards on FDI entry rates (Henisz \& Delios, 2001). One question that motivates this paper is therefore "Are there specific types of experience that can reduce the influence of political hazards on rates of FDI entry?".

We introduce this question in the context of the stages model in which researchers have built on the concept of absorptive capacity (Cohen \& Levinthal, 1990) to demonstrate expansion paths by which firms acquire knowledge and develop skills applicable to new investment environments. Firms, for example, tend to learn more effectively about new cultures from experience gathered in the host 
country or related settings, than from experience gathered in distant cultural settings (Barkema et al., 1996). Learning is also more effective when a firm follows a succession of incremental steps that build its knowledge base, expand its absorptive capacity, and thereby enable learning in more dissimilar environments (Barkema et al., 1997). Hence, experience is likely to provide the greatest benefits to a firm engaged in international expansion when it is gained sequentially, in steps that maximize opportunities to learn about specific dimensions of national environments, while minimizing the extent of uncertainty a firm encounters in its international expa nsions.

\section{HYPOTHESIS DEVELOPMENT}

The stages model is an intuitively appealing model that has received strong support in qualitative work looking at the decisions made in the early stages of a firm's expansion (Sullivan \& Bauerschmidt, 1990). Quantitative empirical work has, however, been less supportive (Turnbull, 1987). We suggest this weakness in the model comes from its relatively narrow conception of international differences as stemming from cultural and market differences. The stages model focus on culture and markets does not emerge as a weakness when the choice set of countries for expansion is constrained to geographically nearby countries in which the structures of policymaking institutions are similar as was the case for the European expansions undertaken by Northern European firms captured by early research on the stages model (Nordström, 1991). When most countries in the world and the concomitant wide variance in national institutional environments are considered, however, the model has its greatest difficulty in explaining cross-country expansion sequences, perhaps again because of the omission of measures of the political environment.

\section{Political Hazards, Experience and Across-Country Expansion}

The ability of a government to credibly commit to a giv en set of policies is of substantial interest to a firm's international expansion strategy (Kobrin et al., 1980). Where policy credibility is low, firms minimize commitments to a market, or avoid investment (Henisz \& Delios, 2001). Uncertainty from the public policy environment magnifies difficulties in collecting, interpreting and organizing the information necessary for a successful entry by foreign direct investment (FDI), increasing the relative costs of FDI, and increasing hurdle rates of return. When policymakers can act unilaterally or have high certainty that a subservient or allied legislature and judicial branch will 
support their actions, future policies are likely to be particularly volatile in response to exogenous shocks, to changes in the identity of policymakers or to changes in the preferences of existing policymakers. Changes that are the result of direct lobbying by host country competitors or incumbents are of particular concern to a firm making an international expansion. We refer to countries characterized by such policymaking structures as politically hazardous.

Although the assertion that firms will eschew politically hazardous markets is not controversial, a stages model perspective would suggest that a firm's sensitivity to political hazards would vary in its profile of prior experience, particularly where that experience profile assists a firm in minimizing the operational impact of political hazards. One such important capability is that to detect and safeguard against opportunistic behavior on the part of a host country government or by partners, buyers, suppliers and competitors that may seek to influence a host country government (Henisz \& Williamson, 1999; Henisz 2000a). Such learning can be applied to develop strategies that mitigate future public and private expropriation hazards (Delios \& Henisz, 2000).

As with learning about culture (Barkema et al., 1996), experience is likely to have its most profound effect on uncertainty reduction, when it is gained in a setting similar to the one in which a FDI entry is being contemplated. Consequently, we expect that a firm with greater levels of experience in environments characterized by a high level of political hazards will have developed more appropriate experience and learning for dealing with uncertainty endemic to other politically hazardous countries and therefore display less sensitivity to a country's level of political hazards.

Hypothesis 1: A firm's stock of experience in politically hazardous countries moderates the negative effect of a country's level of political hazards on rates of FDI entry into that country.

A firm's ability to overcome uncertainty in politically hazardous environments also depends on its ability to focus attention on the resulting managerial challenges relative to other sources of difficulty such as those associated with market or cultural uncertainty. Learning about international operations is an inherently incremental process, which can be most effective when it occurs in a series of sequential steps (Barkema et al., 1996). Consequently firms are likely to follow sequential expansion paths that minimize the requisite amount of new knowledge and learning. If uncertainty about a culture and the policy environment are both high, a substantial amount of learning is required, 
and the difficulties found in mounting a successful investment are magnified. FDI entry is thus less likely. Once learning has occurred over one dimension of this uncertainty, such as culture, uncertainty in the other, is less likely to deter FDI entry. This idea is similar to a double-layered acculturation process in which differences in national and corporate cultures impose a barrier to learning in, and the success of, foreign expansions (Barkema et al., 1996). Accordingly, we expect that when a firm has experience with a given culture, it will be better prepared to enter a country in the same cultural block with high policy uncertainty, and hence display less sensitivity to political hazards when contemplating entering by a foreign subsidiary.

Hypothesis 2: A firm's stock of experience in countries within the same cultural block moderates the negative effect of a country's level of political hazards on rates of FDI entry into that country.

We next consider the efficacy of accumulated experience across types of FDI entry. The stages model identifies a distribution subsidiary as being a suitable mode for learning about local customers and local culture. The suitability extends from the close contact a distribution facility engenders betw een a firm and its consumers. Close contact is essential to acquiring experiential knowledge about "...cultural patterns, structure of the market system, and more importantly, characteristics of individual customer firms..." (Johanson \& Vahlne, 1977: 28). The close contacts are gained through a marketing interface, which creates linkages between a firm and its customers. Although the decision to enter by either a manufacturing or a distribution subsidiary involves the deliberation of a firm's senior management, distribution subsidiaries have a lower commitment of financial and human resources (Johanson \& Vahlne, 1977). Further, senior managers associated with marketing and logistics functions are the ones most likely to be assigned to a distribution subsidiary.

The minimal commitment of senior management in a distribution subsidiary may impose limitations to learning about political hazards. A distribution subsidiary is oriented and structured to acquire information about markets and culture in a host country (Johanson \& Vahlne, 1977). As a low commitment mode of entry, it is not likely that a firm making a distribution entry will be heavily involved in negotiations and bargaining with a host country government. This contrasts to the case of entry by a manufacturing facility which likely involves extensive negotiations along a number of dimensions. Engaging in communications with local authorities for the negotiation of land for a plant, 
contracting for employees, arranging the regulatory or tax concessions for an investment, or securing necessary licenses and permits for international trade and the repatriation of dividends, can help a firm's managers gain an understanding of the political process in a nation (Hillman et al., 1999). As the political process in most countries is highly complex in which the outcomes of political behavior are difficult to evaluate (Boddewyn, 1988), unless linkages are created to insiders in the political process, it is difficult for a firm to understand the rules in a political system, and the dynamics involved in the current issues (Hillman et al., 1999). The cross-functional expertise that accompanies a manufacturing entry, as well as its comparatively greater extent of association and communication with local authorities, relative to a distribution entry, makes it more likely to yield insight into these political processes. Such features likely make the accrual of political hazard mitigation capabilities greater for manufacturing experience than for distribution experience.

Hypothesis 3: A firm's stock of experience in the operation of overseas manufacturing plants moderates the negative effect of a country's level of political hazards on rates of FDI entry into that country.

\section{METHODS}

\section{Setting, Data Sources and Sample}

We test these hypotheses using panel data on the international expansion of Japanese firms.

Japanese firms are a suitable empirical context because they have been a leading investor worldwide in the 1980s and 1990s (UNCTAD, 2001). By 1999, more than 100 countries had received Japanese FDI, with 54 countries possessing at least 30 Japanese FDIs. This provides the country-level variance required to test the effects of political hazards, while controlling for other economic influences.

We derived our sample from the 1,898 manufacturing firms listed on the first and second sections of the Tokyo Stock Exchange as of 1997. We matched this list of firms with the foreign subsidiary data found in the 1986, 1989, 1992, 1994, 1997 and 1999 editions of Toyo Keizai's annual compendium of foreign investment, Japanese Overseas Investment. An edition reputedly contains a complete listing of the stock of each firm's foreign subsidiaries in the year in which it was published (Yamawaki, 1991; Henisz and Delios, 2001). This process yielded 5,894 instances in which a firm had made at least one foreign investment in a host country of which only 94 were lost to casewise deletion due to missing data on political hazards (Henisz, 2000b) or various economic and demographic indicators (World Bank). For the final sample, we needed to be concerned with host 
country-firm pairs in which there was left censoring in the subsidiary foundation history. As few Japanese subsidiaries tend to be divested in the first few years of operations (Delios \& Beamish, 2001), we set initial subsidiary entry not prior to 1980 as our starting date and removed all host country-firm pairs in which a firm made an FDI entry prior to 1980. After this, we had 3,857 cases in which a Japanese firm had made at least one FDI in a host country.

\section{Measures}

Our dependent variable was an indicator variable, $\mathrm{E}_{x i t}$, that took a value of 1 if firm $x$ made an entry in country $i$ at time $t$, otherwise it was zero. Observations started in 1980, continued until an entry occurred, or were right-censored in 1999, if $\mathrm{E}_{x i t}$ was zero in every year $t$ for firm $x$ in country $i$. An entry was a foreign direct investment, not a portfolio investment, that resulted in a firm's first establishment of a foreign subsidiary in the focal host country.

Political hazards. We take this annual time-varying measure from Henisz (2000b). It quantifies the extent to which any one institutional actor-e.g., the executive or a legislative chamber-in a given country is unconstrained in its choice of policies in a given year. The measure i constructed using a spatial model of political interaction that incorporates data on the number of independent veto players and their party affiliations. The main results of the derivation are that (1) each additional veto player (a branch of government that is both constitutionally effective and controlled by a party different from other branches) provides a negative but diminishing effect on the total level of hazards, and (2) hazards decline in the homogeneity (heterogeneity) of party preferences within an opposed (aligned) veto player.

Cultural block distance. Following Barkema et al. (1996), we coded countries into Ronen and Shenkar's (1985) cultural blocks, then made an ordinal ranking of these blocks in terms of their comparative distance from Japan. The nearest cultural block to Japan was scored one, the next most proximate two, and so forth. Results were similar if we used a cultural distance measure.

Investment experience. Using all data we compiled on the history of a firm's investment activity in all years, we computed several experience measures. We first calculated an International experience measure that comprised a firm's experience gathered in all national settings and by all types of entry. We then decomposed international experience into various constituent types of 
experience. We calculated the logarithm of a firm's years of experience in the operation of subsidiaries in countries with above (below) mean levels of political hazards (High (low) hazard country experience); in countries in the same (another) cultural block (Other) Cultural block experience); and in manufacturing (distribution) entries (Manufacturing (distribution) experience).

Interactions. To test the hypotheses we developed six interaction terms. Each interaction w as the multiplicative sum of the mean-centered value for a category of political hazards and experience. For example, we computed the manufacturing experience*political hazards interaction for firm $x$ in country $i$ at time $t$ by multiplying the mean-centered value of manufacturing experience in firm $x$ in year $t-1$ by the mean-centered value of political hazards of country $i$ in year $t-1$.

Firm-level controls. We included positive correlates of FDI activity: firm size (Employment), technological assets ( $R \& D$ intensity), marketing assets (Advertising intensity), and export activity (Export intensity) (Caves, 1996). We included Country spread, a time-varying covariate of the number of countries in which a firm had foreign investments, to control for the competing hypothesis that FDI entry in a politically hazardous country is more likely by firms with diverse international production capabilities because these firms have a valid option to leave (Fagre \& Wells, 1982).

Country controls. We had two measures of market size, GDP per capita and Population, and two of market potential, annual Population growth rate and annual GDP per capita growth rate (Caves, 1996). We measured a country's relative attractiveness for foreign trade (Trade, annual value of exports and imports over GDP) and for foreign investment (FDI, annual flow of FDI over GDP).

Fixed effects. We included annual, country and industry indicator variables. We could not include firm indicator variables as this would expand the number of cells of data to about 500 million thus exceeding the memory capacity needed for model estimation. Results were robust to a model with firm indicator variables for a sub-sample of the 127 firms that had entered 10 or more countries.

\section{Model}

We estimated FDI entry rates using event history analysis, which uses a longitudinal record of events in a sample from a population to examine the influences that a set of covariates have on the event being examined. Our focal event is a firm's first foreign subsidiary establishment in a host country. In the analysis, firm $x$ is considered to be at risk of entering country $i$ in each time period $t$, or 
until an FDI entry occurs. We used an exponential model in which there is no age parametric dependence specified in the functional form of the model. This technique models the rate of a transition from an origin state (e.g., no FDI entry) to a destination state (e.g., FDI entry) as a function of the covariates. Its general form is:

$$
\mathrm{r}_{j k}=\exp \left(\alpha_{j k 0}+\mathrm{A}_{j k 1} \alpha_{k 1}+\mathrm{A}_{j k 2} \alpha_{j k 2} \ldots\right)
$$

where $\mathrm{r}_{k}$ is the transition rate from the origin state $j$ to the destination state $k$, with the observed covariate vector $\mathrm{A}_{j k}$, parameters to be estimated $\alpha_{k}$, and constant $\alpha_{k 0}$. The estimation uses the maximum likelihood method (Blossfeld \& Rohwer, 1995). In our specification, significant positive coefficient estimates indicate FDI entry rates increase when the covariate increases in value.

To estimate this model, we took the base sample of 3,857 first entries by a firm in a country and expanded it into multiple spells that included all firm-country-year combinations among the 665 firms, 68 countries and the annual time periods in which an investment could be made. In each spell, a firm was at risk of entering a country and was treated as right censored unless an FDI entry occurred. Once we divided the data into annual spells and removed combinations in which a nation or firm did not exist (e.g., pre-1986 observations for a firm founded in 1986), we had 816,908 observations.

\section{RESULTS}

Table 1 reports the FDI entry rate models. Model 1 presents the bas eline estimation which includes annual, country and industry indicator variables, country and firm-level controls and cultural distance. Model 2 adds political hazards as a main effect and interacted with international experience. Models 3 to 8 test hypotheses 1,2 and 3. As multicollinearity could confound coefficient estimates for the experience measures and the ir interactions with political hazards, we follow an established procedure of testing each hypothesis in a separate model (Haunschild \& Miner, 1997). Stable coefficient estimates across specifications and Ikelihood tests, in which we compare a model to its baseline, establish that the experience terms and interactions add new information to the model.

In the models, the hypotheses received strong statistical support and, more importantly given the very large sample size, the substantive or economic significance of the coefficient estimates was also quite strong (McCloskely \& Ziliak, 1996). Model 1 presents a baseline specification which includes cultural block distance as the measure of uncertainty stemming from national differences. 
Contrary to conventional stages models predictions (Barkema et al., 1996; Johanson \& Vahlne, 1977), FDI entry rates were not related to a nation's cultural block distance from Japan. When a cultural block distance*international experience interaction was added to model 1 , its coefficient estimate $\mathrm{w}$ as negative, indicating FDI entry rates in culturally close countries became greater with greater levels of international experience. These results hold when we define the sample as countries with below mean levels of political hazards, thus confining uncertainty to the cultural level. Independent of the consideration of political hazards, this result would suggest that Japanese firms' sequence of country choice for international expansion did not follow the stages model. The insignificance of the international experience* political hazards interaction in model 2 supports our conjecture that international experience is too aggregate a measure to inform about the mechanisms by which it changes FDI entry rates.

For the results of the hypothesis tests, we confine our discussion to the economic significance of our results. Hypothesis 1 predicted that a firm's experience in high hazard countries would moderate the negative effect of political hazards on FDI entry rates. Consistent with that hypothesis, firms with high experience in hazardous countries (one standard deviation above the mean level of experience - 36 years) had a predicted probability of enter ing another hazardous country 58.5 percent greater than a firm with no experience in hazardous countries. Similar increases in the probability of entry were observed for countries at the mean level or with low levels of political hazards. This relationship differs substantively from the effect of firm-level experience in low hazards countries, in which the effect on FDI entry rates into low hazards countries was nearly three times larger than in politically hazardous countries (a change of 147.5 versus 59.2 percent).

Hypothesis 2 predicted that experience in a cultural block would moderate the deterring effect of political hazards on entries in that block. Moving from a cultural block experience level of zero, to a high experience level (one standard deviation above the mean -8 years) increased the predicted probability of FDI entry by 14.1 percent in a low hazards setting, which was less than the 19.0 percent increase in a high hazards setting. Meanwhile, experience in other cultural blocks did not moderate the influence of political hazards. At all levels of experience in other cultural blocks, FDI entry rates in low hazards countries were 18.9 percent greater than those in high hazard countries. 
Hypothesis 3 predicted a moderating role for manufacturing experience on the negative relationship between political hazards and FDI entry. Manufacturing experience contributes positively to FDI entry probabilities in high hazards settings. A firm with a high level (55 years) of manufacturing experience had a 75.8 percent increase in the predicted probability of FDI entry when political hazards were high, compared to a 29.9 percent increase when political hazards were low. Meanwhile, the accumulation of distribution experience resulted in a 41.0 percent increase in the predicted probability of FDI entry into low hazard countries, but a 12.0 percent decrease where political hazards were high. We examined this result further by splitting the sample into two subsamples: first entries made by a distribution facility and first entries made by a manufacturing plant. The results show that manufacturing experience provides a similar positive moderation of political hazards for both distribution and manufacturing entries, with the negative moderating influence of distribution experience confined to manufacturing entries.

\section{DISCUSSION}

We have considered the effect of international experience of various types on the process of international expansion in a stages model we extended to include consideration of cross-national and temporal variation in the credibility of the policy environment. We find that firms that have followed a sequential process of international expansion exhibit a lower sensitivity to the deterring effect of political hazards. The results provide substantial corroborating evidence for the underlying theoretical premise of the stages model regarding the impact of uncertainty and accumulated experience on a firm's ability to overcome national differences in institutional environments. Importantly, however, this corroborating evidence comes about when uncertainty emanating from the policy environment is modeled as part of national institutional variations. When we only considered the cultural environment, as in our model 1, Japanese firms seem to make investment decisions irrespective of the level of uncertainty in the host environment. This result for uncertainty stemming from the cultural environment, which contradicts conventional stages models predictions, might extend from an absence of clos e cultural counterparts to Japan (Ronen \& Shenkar, 1985), where the contrast between close cultural counterparts and remote cultural countries provides a strong influence on foreign expansion patterns and outcomes (Barkema, et al 1996). 
When we included the policy environment - specifically, a measure of the feasibility of policy change based upon the structure of political institutions; however, we found a robust relationship between the extent of policy uncertainty and FDI entry rates. We found evidence that a firm tried to minimize the amount of new information, and uncertainty, with which it must contend, by expanding into settings in which it is familiar with at least one dimension (political or cultural) of the institutional environment. Similarly, a firm tries to accumulate experience in developing relationships between senior management and host country actors as occurs via direct investment in manufacturing operations, as made prior to entering hazardous countries. By contrast, the market and cultural based experience provided by a distribution facility is of the greatest assistance when entering low hazard environments.

This study also advances research on experience effects in internationalization (Erramilli, 1991) by moving beyond aggregate measures of experience, which may proxy for unobserved differences in a firm's managerial competence, rather than the type of knowledge and skills acquisition necessary for a firm to expand in a sequential process. By showing that firms with greater levels of specific types of experience have higher rates of FDI entry into those countries where this experience is of particular value, our study reinforces the importance of measuring and testing experience effects in a way that aligns with the uncertainty that is to be overcome and the precise capabilities a firm needs to develop.

\section{Limitations and Future Directions}

Although this study was rich in its number s of host countries and firms and in the time period examined, it was limited to FDI entries by Japanese firms The focus on Japanese firms creates a case in which there were not any countries in the same cultural block in Japan (Ronen \& Shenkar, 1985), thereby deemphasizing the influence of the cultural dimension, while creating a greater emphasis on the policy environment. In this sense, the sample presents a strong case for testing the influence of the political dimension over the cultural dimension of national institutional environments. Another limitation is our simplification of multinational entry strategies to the decision to enter in isolation from other simultaneous decisions such as entry mode. Future work could refine both measures of the national institutional environment to encompass legal, political and electoral rules as well as our 
measures of international experience so as to draw a tighter association between experience and learning. Refined measures and additional qualitative evidence could also show what specific techniques and strategies firms employ to overcome uncertainty in the policy environment. One step to reinforce the predictive validity of our measures is to examine the performance implications of decisions made by firms with differing experience levels (Barkema et al., 1996). Examining performance would help establish if the investment sequences we have identified increase the chances of making a successful FDI entry.

\section{Conclusion}

This study extended ideas based in a stages model of international expansion to incorporate a sophisticated perspective on the impact of uncertainty in a country's policy environment on a firm's expansion strategy. We highlight that specific types of experience plausibly generate the capabilities required for political hazard mitigation, which in turn influence the sensitivity of a firm's rates of FDI entry to policy uncertainty. The implication from a theoretical perspective is that the policy environment injects uncertainty into foreign markets independent of market and cultural environments, and this policy uncertainty should be considered in theoretical treatments and practical applications of sequential entry models. These theoretical arguments and the empirical evidence in support thereof bring the stages model of internationalization in closer concordance with the large body of empirical research emphasizing the importance of political change and political processes for international expansion strategies across time.

\section{REFERENCES}

Barkema HG, Bell JHJ, Pennings JM. 1996. Foreign entry, cultural barriers, and learning. Strategic Management Journal 17:151 - 166.

Barkem a HG, Shenkar O, Vermeulen F, Bell JHJ. 1997. Working abroad, working with others: How firms learn to operate international joint ventures. Academy of Management Journal 40: 426442.

Benito GRG, Gripsrud G. 1992. The expansion of foreign direct investments: Discrete rational location choices or a cultural learning process. Journal of International Business Studies 23(3): 461-476.

Blossfeld HP, Rohwer G. 1995. Techniques of Event History Modeling. Lawrence Erlbaum Associates: Mahwah, New Jersey.

Boddewyn J. 1988. Political aspects of MNE theory. Journal of International Business Studies 15: 341-363.

Caves RE. 1996. Multinational Enterprise and Economic Analysis (2nd ed.). Cambridge University Press: New York.

Cohen WM, Levinthal DA. 1990. Absorptive capacit y: A new perspective on learning and innovation. 
Administrative Science Quarterly 35: 128-152.

Cyert RM, March JG. 1963. A Behavioral Theory of the Firm. Prentice-Hall: Englewood Cliffs.

Davidson W. 1980. The location of foreign direct investment activity: Country characteristics and experience effects. Journal of International Business Studies 11(1): 9-22.

Delios A, \& Beamish PW. 1999. Ownership strategy of Japanese firms: Transactional, institutional and experience influences. Strategic Management Journal 20(10): 915-933.

Delios A, Beamish PW. 2001. Survival and profitability: The roles of experience and intangible assets in foreign subsidiary performance. Academy of Management Journal 44(5): 1028-1038.

Delios A, Henisz WJ. 2000. Japanese firms' investment strategies in emerging economies. Academy of Management Journal 43: 305-323.

Eriksson K, Johanson J, Majkgård A, Sharma DD. 1997. Experiential knowledge and cost in the internationalization process. Journal of International Business Studies 28(2): 337-360.

Erramilli MK. 1991. The experience factor in foreign market entry behavior of service firms. Journal of International Business Studies 21: 479-501.

Fagre N, Wells LT. 1982. Bargaining power of multinational and host governments. Journal of International Business Studies 13: 9-23.

Haunschild PA, Miner AS. 1997. Modes of interorganizational imitation: The effects of outcome salience and uncertainty. Administrative Science Quarterly 42(3): 472-500.

Henisz WJ. 2000a. The institutional environment for multinational investment. Journal of Law, Economics and Organization 16: 334-364.

Henisz WJ. 2000b. The institutional environment for economic growth. Economics and Politics 12: 131.

Henisz WJ, Delios A. 2001. Uncertainty, imitation, and plant location: Japanese multinational corporations, 1990-1996. Administrative Science Quarterly 46(3): 443-475.

Henisz WJ, Williamson OE. 1999. Comparative economic organization -- Within and between countries. Business and Politics 1: 261- 277.

Hillman AJ, Hitt MA. 1999. Corporate political strategy formulation: A model of approach, participation and strategy decisions. Academy of Management Review 24: 825-842.

Johanson J, Vahlne JE. 1977. The internationalization process of the firm -- A model of knowledge development and increasing foreign market commitments. Journal of International Business Studies 8(1):23-32.

Kobrin S, Basek J, Blank S, La Palombara J. 1980. The assessment and evaluation of noneconomic environments by American firms. Journal of International Business Studies 11: 32-47.

Lu JW. 2001. Intra- and inter-organizational imitative behavior: Institutional influences on Japanese firm's entry mode choice. Journal of International Business Studies, 33(1): 19-37.

Luostarinen R. 1980. Internationalization of the Firm. The Helsinki School of Economics: Helsinki, Finland.

McCloskey DN, Ziliak ST. 1996 The standard error of regressions Journal of Economic Literature 34(1): 97-114.

Nordström KA. 1991. The Internationalization Process of the Firm. Searching for New Patterns and Explanations. Institute of International Business, Stockholm School of Economics: Stockholm, Sweden.

North D. 1990. Institutions, Institutional Change, and Economic Performance. Cambridge University Press: Cambridge, MA.

Ronen S, Shenkar O. 1985. Clustering countries on attitudinal dimensions: A review and synthesis. Academy of Management Review 10(3): 435-454.

Sullivan D, Bauerschmidt A. 1990. Incremental internationalization: A test of Johanson and Vahlne's thesis. Management International Review 30(1): 19-30.

Turnbull PW. 1987. A challenge to the stages theory of the internationalization process. In PJ Rosson, SD Reid (eds.), Managing Export Entry and Expansion. Praeger: New York.

UNCTAD. 2001. World Investment Report 2001: Promoting Linkages. United Nations: New York and Geneva.

Yamawaki H. 1991. Exports and foreign distributional activities: Evidence on Japanese firms in the United States. Review of Economics and Statistics, 73: 294-300. 
TABLE 1

Exponential Estimation of Rates of FDI Entry Across Countries ${ }^{\text {a,b }}$

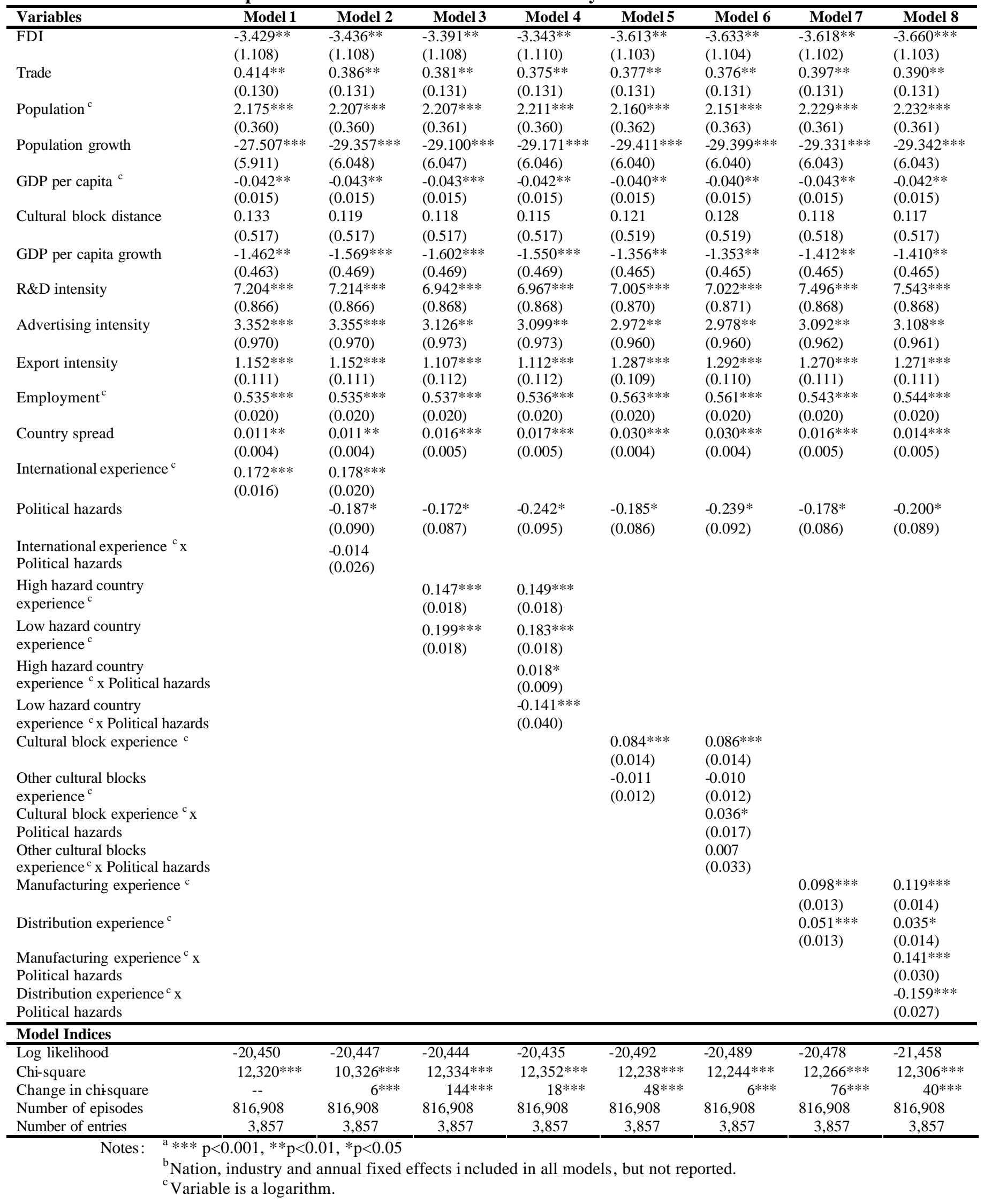

